\title{
A Methodology for Assessing Blast Protection in Explosive Ordnance Disposal Bomb Suits
}

\author{
Cameron "Dale" Bass \\ Martin Davis \\ Karin Rafaels \\ University of Virginia, Charlottesville, USA \\ Mark "Steve" Rountree \\ Robert M. Harris
}

U.S. Army Medical Research and Materiel Command, Ft. Detrick, MD, USA

Ellory Sanderson

Walter Andrefsky

Gina DiMarco

U.S Army Aberdeen Test Center, Aberdeen Proving Grounds, MD, USA

\section{Michael Zielinski}

\section{U.S. Army Research, Development and Engineering Command - Natick Soldier Center, Natick, MA, USA}

To reduce human casualties associated with explosive ordnance disposal, a wide range of protective wear has been designed to shield against the blast effects of improvised explosive devices and munitions. In this study, 4 commercially available bomb suits, representing a range of materials and armor masses, were evaluated against 0.227 and $0.567 \mathrm{~kg}$ of spherical C-4 explosives to determine the level of protection offered to the head, neck, and thorax.

A Hybrid III dummy, an instrumented human surrogate [1], was tested with and without protection from the 4 commercially available bomb suits. 20 tests with the dummy torso mounted to simulate a kneeling position were performed to confirm repeatability and robustness of the dummies, as well as to evaluate the 4 suits. Correlations between injury risk assessments based on past human or animal injury model data and various parameters such as bomb suit mass, projected area, and dummy coverage area were drawn. blast pressure human surrogate bomb suits injury risk head injury
neck injury thoracic injury

\section{INTRODUCTION}

Terrorist bombings in the USA are becoming frequent events whether by foreign terrorists like the World Trade Center bombing or by domestic terrorists like the Oklahoma City, Atlanta Olympic Park, or multiple women's clinic bombings. These increasingly common events translate into a greater need for explosive ordnance disposal (EOD) technicians and a greater risk incurred by the many

Correspondence and requests for offprints should be sent to Karin Rafaels, Center for Applied Biomechanics, 1011 Linden Ave., Charlottesville, VA 22902, USA. E-mail: <rafaels@virginia.edu>. 
EOD technicians employed by the military and law enforcement agencies.

In the past, the use of protective equipment has meant an overwhelming weight burden and/or the loss of dexterity and eye-hand coordination to the detriment of the render-safe mission. The advent of newer materials with greater protective capabilities and lighter weight represents a significant improvement in personnel blast protection. While newer bomb suits can remain intact against realistic charge weights when tested on human surrogates, the ultimate response of the living human to these blast insults remains to be determined.

The principal objective of this study was to develop and test an objective methodology for EOD bomb suits that can evaluate the risk of human injuries from explosive blasts. These injuries include blast injuries to the head and thorax; blunt trauma to the head, neck and thorax; and burns. Essential elements in the development of this procedure for evaluating the risk of injury while wearing EOD bomb suits are

1. Robust dummy surrogate with established and applicable injury criteria, positioned in a realistic manner representative of EOD (i.e., kneeling position);

2. Robust instrumentation-data handling consistent with the response;

3. Accurate positioning-distance to the improvised explosive device (IED) must be consistent and quantifiable;

4. Repeatable, quantifiable threat (IED) spherical charge center detonated;

5. Validation against a biofidelic surrogate (cadaver and/or animal model).

Building on past blast testing, the first four of these elements are satisfied by the procedure developed in this study and act to provide an objective criterion for injury measurements and injury protection measurements while ensuring that the resulting criterion is as applicable as possible to the conditions experienced in the real world. Direct validation against a biofidelic surrogate (cadaver and/or animal model), the fifth element, has not been performed, however, and would be valuable.
This study is intended to address the assessment of blast protection only. It is important to separate blast and fragmentation behavior in any EOD test methodology to limit the risk of damage to blast instrumentation from fragmentation. Fragmentation and penetration resistance may be assessed using standard penetration test techniques such as U.S. military standard MIL-STD662F [2] or the NATO standard STANAG-2920 [3], which use standard fragment simulating projectiles (FSP) into armor materials at various impact velocities. Such a penetration assessment should include the effect of suit components as potential secondary missiles under blast loading.

\section{BACKGROUND AND HUMAN EFFECTS FROM BLAST}

Explosive detonation in the open air produces a shockwave followed by a blast wind. Human injury from these blasts has been studied extensively for many years [4]. However, many of these studies involve ideal planar blast waves in the far field (e.g., ideal Friedlander waves). Unfortunately, when an individual is in close proximity to a blast, yet protected from immediate death, understanding the explosive event becomes more difficult. In the near field, blast may not present as a point source, nor have the pressure waves developed into the classic Friedlander form. This complicates the analysis using existing injury criteria.

Many of the injury criteria developed for blast injuries, specifically blast lung injuries, have been developed using data from simple square wave or simple Friedlander wave forms. There may be, however, a significant influence from complex blast waves, especially behind body armor or textiles, or in enclosed spaces [5]. Increasing the rate of pressure application on the leading edge increases the risk of lung damage, and complex blast waves with multiple peaks may exacerbate the damage relative to simple wave forms [6]. However, injury criteria for general complex blast interactions with human tissues are not extant. Injury prediction based on chest wall velocity has been recommended; however, this procedure has limited experimental validation [7]. 
In addition, the blast environment may be exacerbated by clothing or suits worn by personnel. For example, textiles may increase the effect of blast waves $[8,9]$. Specifically, ballistic vests may increase blast injuries [10]. Cooper and Jonsson recommend the use of a decoupling layer to mitigate the potential for such exacerbation [4]. Such decoupling layers have not been generally used in U.S. body armor.

\section{METHODOLOGY}

\subsection{Dummy}

A 50th percentile male Hybrid III anthropomorphic (automobile crash test) dummy (First Technology Safety Systems, Inc., USA) was used in this test series. The upper torso is shown in Figure 1. The torso was mounted on a lower limb apparatus especially designed for this test. The complete dummy fixture was incorporated into a charge-positioning fixture supported by a metal platform. The test dummy was placed in a common EOD position (kneeling) shown in Figure $1 \mathrm{~b}$. The kneeling position was specified to produce a significant risk of blunt head trauma to an unprotected dummy, while representing a common EOD work position. Other EOD positions were considered (e.g., standing), but excluded because these suits are meant to be complemented with proper demining footwear $[11,12]$. Due to variations in dummy response with temperature, the internal temperature of each dummy was monitored, and the dummy was stored in a temperature-controlled environment at approximately $22{ }^{\circ} \mathrm{C}$ overnight and on non-test days. Mean testing temperature of the dummy was $23 \pm 3{ }^{\circ} \mathrm{C}$.

The Hybrid III dummy was selected for this test series because new development of biofidelic surrogates can be extraordinarily expensive. The Hybrid III series is widely used in the automobile industry for evaluation of the effects of blunt trauma on humans, so injury criteria exist that may be appropriate in evaluating blast injuries. The dummies are also relatively inexpensive and robust and therefore suitable for repeated tests.

\subsection{Test Fixture}

The test was conducted in a large building with the floorplan as shown in Figure 2a. A blast resistant positioning fixture, as drawn in Figure $2 b$, was used to support and position the IED. The fixture was placed at least $4 \mathrm{~m}$ from the wall to prevent blast reflections. This positioning fixture was developed by a U.S.-Canadian collaboration including the U.S. Army Communications and Electronic Command (CECOM), Canadian Center for Mine Action Technologies (CCMAT), U.S. Army Aberdeen Test Center (ATC), and the University of Virginia-Impact Biomechanics Program. The fixtures allow accurate positioning for each shot to be within $\pm\left(3 \times 10^{-3}\right) \mathrm{m}$ to reference locations in each spatial axis. (a)

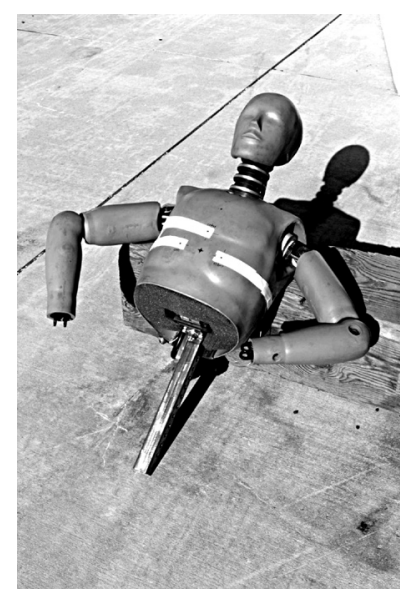

(b)

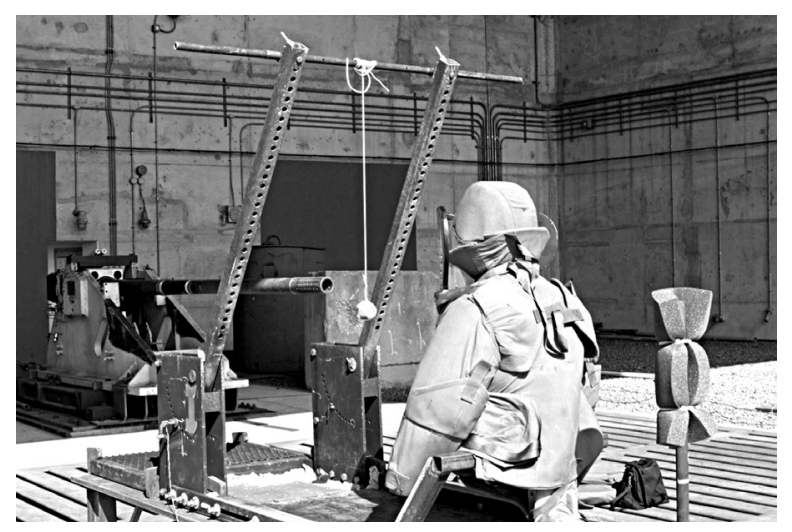

Figure 1. (a) Hybrid III upper torso and (b) nominal kneeling position. 
(a)

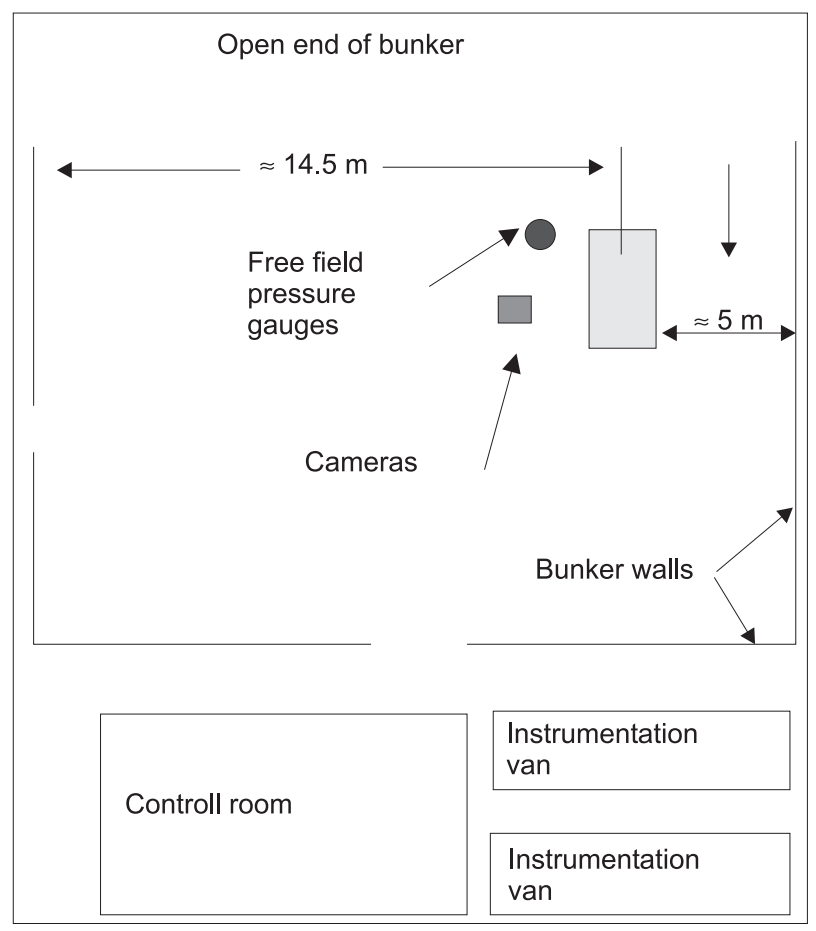

(b)

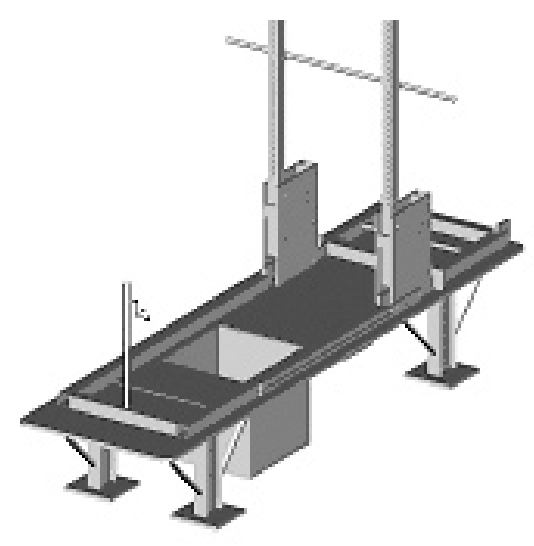

Figure 2. (a) Test site plan view and (b) position fixture drawing.

\subsection{Instrumentation and Data Acquisition}

A Hybrid III anthropomorphic dummy was instrumented to measure pressure, sternum acceleration, neck moments and forces, and acceleration in the head and chest as shown in Table 1. Triaxial acceleration data was collected at head and chest locations. Upper neck load cells measured forces and moments in the $x, y$, and $z$ axes from frontal, lateral, or combined impacts. In addition, pressure sensors were used in the thorax and head to determine the risk of blast injuries to the lungs and ears. For the first test, the sampling frequency was $2 \times 10^{5} \mathrm{~Hz}$ with hardware antialiasing filtering at $4 \times 10^{4} \mathrm{~Hz}$. The remaining sensors were sampled at $8 \times 10^{5} \mathrm{~Hz}$ with hardware antialiasing filtering at $4 \times 10^{4} \mathrm{~Hz}$. It is essential to perform hardware antialiasing filtering for blast
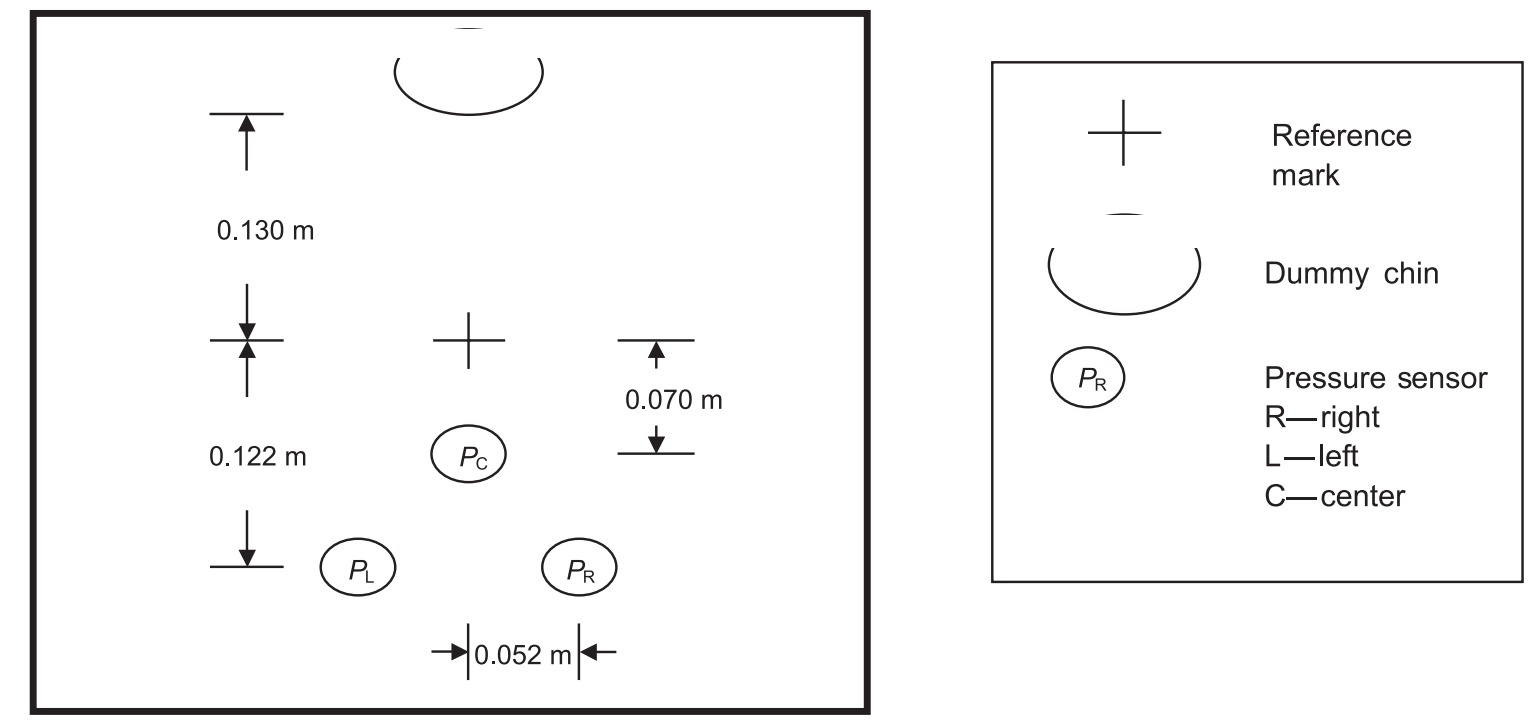

Figure 3. Thoracic pressure sensor placement. 
TABLE 1. Instrumentation

\begin{tabular}{|c|c|c|c|}
\hline Transducer & Location & Data Collected & Notes \\
\hline \multirow[t]{2}{*}{ Accelerometer } & Head, center of gravity & Triax accelerometer & $\begin{array}{l}\text { Endevco 7270A-6k } \\
\text { (Endevco Corp., USA) }\end{array}$ \\
\hline & Chest, center of gravity & Triax accelerometer & $\begin{array}{l}\text { Endevco 7270A-6k } \\
\text { (Endevco Corp., USA) }\end{array}$ \\
\hline $\begin{array}{l}\text { Load cell (Robert A. } \\
\text { Denton, Inc., USA) }\end{array}$ & Upper neck & Forces and moments & Frontal, lateral impacts \\
\hline Accelerometers & Sternum & Acceleration & $\begin{array}{l}\text { Endevco 7270A-6k } \\
\text { (Endevco Corp., USA) }\end{array}$ \\
\hline $\begin{array}{l}\text { Displacement transducer } \\
\text { (SpaceAge Control, } \\
\text { Inc., USA) }\end{array}$ & Sternum & $\mathrm{X}$ displacement & Chest deflection \\
\hline \multirow[t]{4}{*}{$\begin{array}{l}\text { Pressure Transducer/ } \\
\text { Gauge }\end{array}$} & Thorax & Frontal pressure & $\begin{array}{c}\text { Kulite LQ-125 (Kulite Semiconductor } \\
\text { Products, Inc., USA) }\end{array}$ \\
\hline & $\begin{array}{l}\text { Skin surface, ear } \\
\text { location }\end{array}$ & Pressure & $\begin{array}{c}\text { Endevco } 8530 \\
\text { (Endevco Corp., USA) }\end{array}$ \\
\hline & Free field & Pressure & $\begin{array}{c}\text { PCB 102M114 } \\
\text { (PCB Piezotronics, USA) }\end{array}$ \\
\hline & Free field & Pressure & $\begin{array}{c}\text { Endevco } 8530 \\
\text { (Endevco Corp., USA) }\end{array}$ \\
\hline $\begin{array}{l}\text { Thermocouple (Omega } \\
\text { Engineering, Inc., USA) }\end{array}$ & Spine box & Internal temperature & Static \\
\hline
\end{tabular}

testing as high frequency spectral content from piezoresistive sensors may be large. After each test, sensors were inspected for damage and were replaced as required. The chest pressure sensors used were fastened to the dummy skin using double-sided tape and positioned according to the diagram in Figure 3.

\subsection{IEDs}

Modeling the blast itself is a complicated issue. Nominally, identical IEDs may have widely different behavior, and blast characteristics may change considerably depending on construction technique, method of employment and environmental conditions. In addition, real IEDs are diverse and may be difficult to handle safely. To develop an objective test procedure, a test condition should be realistic, yet repeatable, a balance that limits the number of tests and costs necessary to effectively characterize the performance of protective equipment. This suggests that IEDs should be simulated with a relatively well-characterized explosive and should be formed into a nominally identical geometry and mass.

In this study, simulated IEDs were produced using 0.227 and $0.567 \mathrm{~kg}$ of C-4, formed into spheres of nominally identical size and weight. The two charge weights were selected to best represent

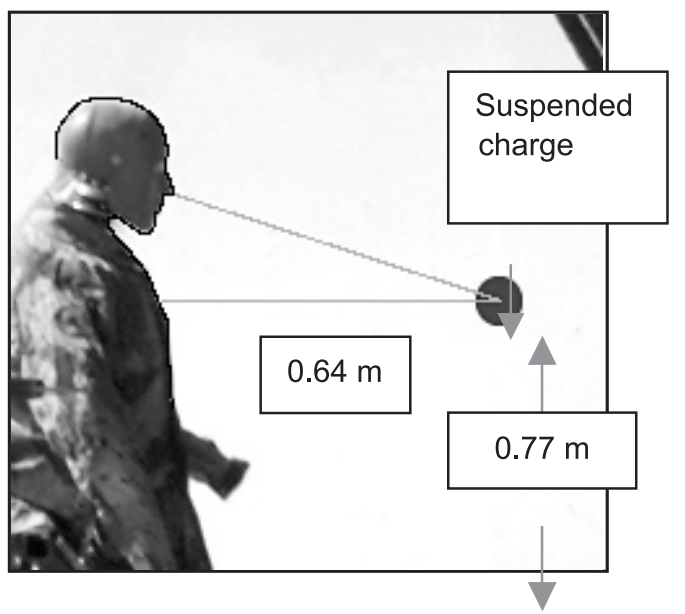

Figure 4. Nominal position relative to the center of the improvised explosive device (IED) surrogate-radial lines at $0^{\circ}$ and $20^{\circ}$. 
a potentially survivable range of the broad spectrum of IEDs worldwide. The use of spherical C-4 charges provides greater repeatability from test to test. These simulated IEDs were statically detonated using an M-6 electric blasting cap placed in the center of the sphere. The charge was suspended from a positioning apparatus in front of the dummy as shown in Figure 4. The IEDs were suspended $0.77 \mathrm{~m}( \pm 0.001)$ in height from a reference point on the apparatus floor, $0.64 \mathrm{~m}$ $( \pm 0.003)$ from the sternum, and $0.595 \mathrm{~m}( \pm 0.007)$ from the nose, measured perpendicular to the ground.

To assess IED performance relative to each other, two free field pressure sensors recorded the pressure time history of the blast, as shown in Figure 2. A gauge oriented face-on to the blast was

\subsection{Suits}

The four bomb suits chosen for this test series, termed suit $\mathrm{A}$, suit $\mathrm{B}$, suit $\mathrm{C}$, and suit $\mathrm{D}$, represent a sample of EOD personal protective equipment that is commercially available. The suits are shown in Figure 5. The protective equipment was placed on the dummy per manufacturers' instructions to ensure consistent placement and provide consistent coverage. The bomb suits were supplied by U.S. Army Project Manager-Soldier Equipment. All bomb suits had been used, but were in good, serviceable condition. The components of each suit type were configured using the least worn individual components (determined by gross visual inspection) from each type of ensemble. Some components were tested multiple times, as explained below.

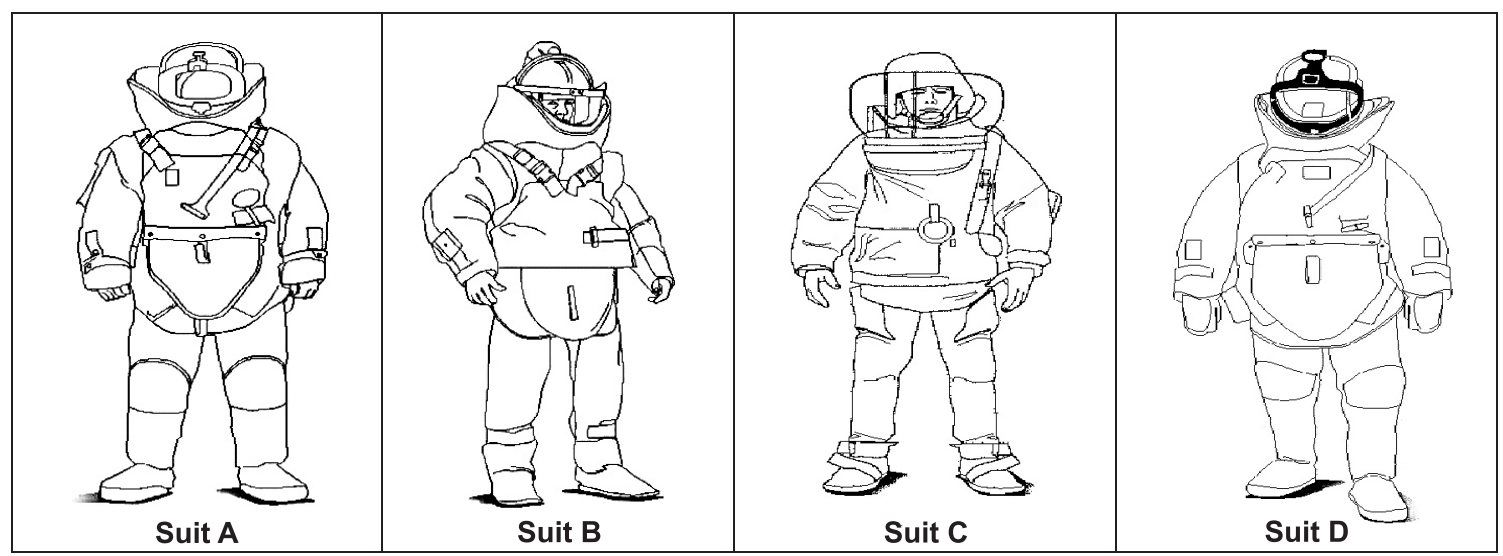

Figure 5. Suits used in testing.

located at $1.83 \mathrm{~m}( \pm 0.01)$ horizontally from the center of the IED, at the level of the ear. A side-on gauge was located at $1.94 \mathrm{~m}( \pm 0.01)$ horizontally from the center of the IED, also at the level of the ear. This provides quality assurance comparisons of like charges and provides a data set to directly compare against existing blast injury criteria [13]. Each condition had limited numbers of IED shots and relatively small spreads in pressure response.

In this study, the boundary conditions were arranged so that the blast wave was essentially ideal. The charge approximates a point source in a test area that does not produce reflections from the side walls or the roof. There may, however, be curvature effects from the near field blast and complex wave interactions behind the body armor.
Table 2 lists component weights of the suits, helmets, and visor and visor projected area. For blunt trauma protection against IED blasts, there is a significant tradeoff between ergonomics and protection. For instance, a larger mass helmet may provide greater protection against blunt force trauma, but may be more difficult to wear thus having a detrimental impact on the render safe operation. Such tradeoffs underscore the value of a complete assessment of bomb suit function as a system that includes the operator. This may include an assessment of the ergonomics of the suit, protection against fragments, and protection against blunt trauma.

One of the issues with using Hybrid III dummies is that the head form does not allow proper fit of the integral ear protection built into the helmets. 
TABLE 2. Suit Parameters

\begin{tabular}{lccccc}
\hline Item & & Suit A & Suit B & Suit C & Suit D \\
\hline Body armor weight $(\mathrm{kg})$ & & 29 & 31 & 28 & 31 \\
Helmet weight $(\mathrm{kg})$ & 2.9 & 3.1 & 3.0 & 2.8 \\
Visor weight $(\mathrm{kg})$ & & 1.4 & 2.1 & 3.6 & 1.5 \\
Visor projected $\mathrm{area}\left(\mathrm{m}^{2}\right)$ & & 0.0656 & 0.0845 & 0.1512 & 0.0681 \\
Jacket weight $(\mathrm{kg})$ & & 13 & 12 & 12 & 13 \\
Chest plate $(\mathrm{kg})$ & & 3.0 & 3.6 & $2.9^{*}$ & 3.1 \\
Abdominal plate $(\mathrm{kg})$ & Mid & $\mathrm{NA}$ & 1.2 & $\mathrm{NA}$ & $\mathrm{NA}$ \\
& Lower & 1.2 & 1.9 & $\mathrm{NA}$ & 2.0 \\
& Total abdominal & 1.2 & 3.1 & $\mathrm{NA}$ & 2.0 \\
Trousers $(\mathrm{kg})$ & & 5.4 & 4.8 & 6.0 & 7.1 \\
Total tested suit weight $(\mathrm{kg})$ & & 22 & 24 & 21 & 22 \\
\hline
\end{tabular}

Notes. *-visor and chest plate are one piece.

Thus, the ear trauma predictions may potentially be higher than the level of injury actually incurred with field use.

\subsection{Test Matrix}

The test matrix for this study included two primary test variables. These were charge weight and level of bomb suit protection, in a standardized position relative to the center of the explosive blast as shown in Table 3. In addition, the smallest charge size IED test was repeated three times with an unprotected dummy as a control. As a baseline for comparison between tested bomb suits, a minimum of two shots was performed for each bomb suit against the smallest threat $(0.227 \mathrm{~kg}$ of C-4). The test dummy was placed in a standardized kneeling position, simulating a realistic position for an EOD technician working in close proximity (near field) to an explosive device.

\section{RESULTS}

Sensor data from the IED blasts was evaluated for both repeatability under a given condition (sensitivity) and the ability to discern differences in injury performance with different suits (specificity). This evaluation includes tests both with and without an EOD suit. To provide effective simulation of injuries actually received in IED blast incidents, the types of injuries evaluated are blunt head trauma, blunt neck trauma, blunt thorax trauma, blast thorax trauma (blast lung). A key issue in the evaluation of the blunt injury data is whether the standard injury criteria for the Hybrid III dummies may be successfully used since the dynamic time scale of the blast and subsequent dummy response may be different from that seen in automobile crashes. The blast event was generally short compared to the usual durations of impact events for the Hybrid III dummies. The pressure response of the blast was completed in a duration much shorter than a millisecond, with acceleration response being

TABLE 3. Test Matrix for the Hybrid III 50th Percentile Male Dummy

\begin{tabular}{|c|c|c|c|c|c|c|c|c|}
\hline Test & Suit & $\begin{array}{c}\text { Charge } \\
\text { Weight C-4 (kg) }\end{array}$ & Test & Suit & $\begin{array}{c}\text { Charge } \\
\text { Weight C-4 (kg) }\end{array}$ & Test & Suit & $\begin{array}{c}\text { Charge } \\
\text { Weight C-4 (kg) }\end{array}$ \\
\hline 1 & $\mathrm{C}$ & 0.227 & 8 & $B$ & 0.567 & 15 & $\mathrm{C}$ & 0.227 \\
\hline 2 & $\mathrm{C}$ & 0.227 & 9 & $D$ & 0.227 & 16 & $D$ & 0.567 \\
\hline 3 & $\mathrm{C}$ & 0.227 & 10 & $D$ & 0.227 & 17 & $A$ & 0.567 \\
\hline 4 & $\mathrm{C}$ & 0.567 & 11 & $A$ & 0.227 & 18 & BLS $^{*}$ & 0.227 \\
\hline 5 & $\mathrm{C}$ & 0.567 & 12 & $A$ & 0.227 & 19 & BLS $^{*}$ & 0.227 \\
\hline 6 & B & 0.227 & 13 & $A$ & 0.567 & 20 & $\mathrm{BLS}^{*}$ & 0.227 \\
\hline 7 & $\mathrm{~B}$ & 0.227 & 14 & $\mathrm{C}$ & 0.227 & & & \\
\hline
\end{tabular}

Notes. *-baseline shot-Nomex suit only. 
approximately $1 \mathrm{~ms}$ or greater. As the simulated IEDs were not fragmentation IEDs, the bomb suits did not suffer any penetrations. Many visors completely separated from the helmet late in the blast event. While this may be protective against the initial blast and fragmentation, separation may not be desirable for protection against debris or secondary blasts.

\subsection{Head Injury (HIC)}

As shown in the epidemiology data, fatalities from head injuries are very significant in IED blasts. These injuries may be caused by direct blast impingement on the head or by blunt trauma from impingement of the protective gear. One injury criterion commonly used with the Hybrid III dummy head/neck complex is the head impact criterion (HIC) for concussive head injury [14] based on the Wayne State Concussive Tolerance Curve [15]. HIC includes the effect of acceleration time history $a(t)$ and the duration of the acceleration. $H I C$ is defined as

$$
H I C=\left\{\left(t_{2}-t_{1}\right)\left[\frac{1}{t_{2}-t_{1}} \int_{t_{1}}^{t_{2}} a(t) d t\right]^{2.5}\right\}_{\max },
$$

where $t_{1}$ and $t_{2}$ are the initial and final times (in s) of the interval during which $H I C$ attains a maximum value. Therefore, HIC includes the effect of head acceleration and duration. An HIC value of 1000 is specified as the level for onset of severe head injury. The maximum time duration of $\mathrm{HIC}$ is limited to a specific value, usually $0.015 \mathrm{~s}$. Physically, HIC predicts that large accelerations may be tolerated for short times. HIC is evaluated using the head triaxial accelerometer at the head center of gravity. This standard is often used to assess head injury using Hybrid III dummies in frontal impacts. However, HIC is based on human cadaver and animal impact data with durations that are usually $5 \mathrm{~ms}$ or greater, with extremely limited data less than $1 \mathrm{~ms}$ in duration. The acceleration effects of near field blasts are often shorter than $5 \mathrm{~ms}$, raising questions about the applicability of the usual injury criteria to IED high rate blast head trauma.

HIC values for unprotected and protected kneeling dummies calculated with a $1 \times 10^{4} \mathrm{~Hz}$ lowpass filter are shown in Figure 6 for IED blast strengths of $0.227 \mathrm{~kg}$ and $0.567 \mathrm{~kg}$ of C-4. These HIC values for replicated tests show good repeatability among charge sizes, though the number of repeated tests is limited. For the four helmet/visor types and the baseline shot (BLS) there is a substantial difference between the response at the smaller charge size $(0.227 \mathrm{~kg}$ of C-4) and the larger charge size $(0.567 \mathrm{~kg}$ of C-4). In addition, there are large differences in $H I C$ between the suits at the same charge size. These differences

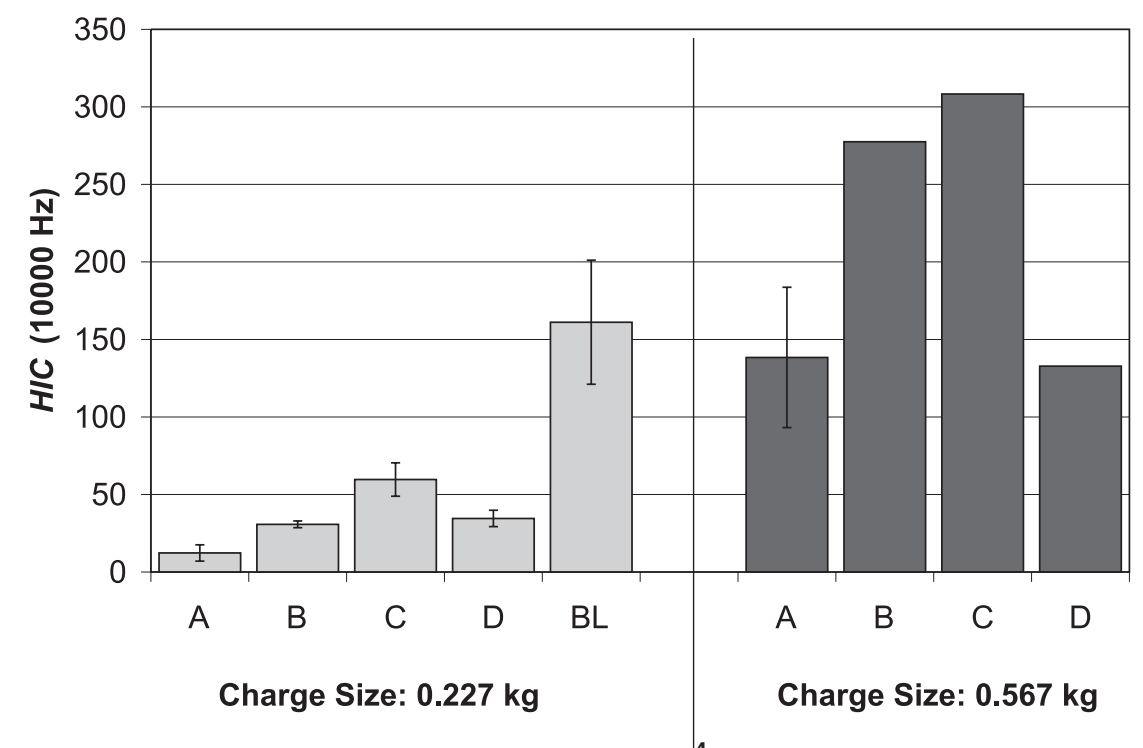

Figure 6. Variation of head impact criterion $(H I C)\left(1 \times 10^{4} \mathrm{~Hz}\right)$ with suit type for the Hybrid III 50th percentile male dummies in the kneeling position-typical injury tolerance $=1000\left(1 \times 10^{4} \mathrm{~Hz}\right.$ lowpass filter-mean value with standard deviation error bars). Notes. BL_baseline. 
are generally outside the single standard deviation bounds, though the limited number of repeated tests prevents evaluation of statistical significance between the test conditions. The relative ordering of suits $\mathrm{A}, \mathrm{B}$, and $\mathrm{C}$ is maintained for $\mathrm{HIC}$ between charge sizes. However, the response for A at the larger charge size is larger than that for $\mathrm{D}$, in contrast to the response at the smaller charge size. Therefore, this potential injury measure appears to differentiate response between suits and between charge sizes. In addition, all suits offer protection relative to the unprotected baseline, and suit $\mathrm{C}$ has the highest $H I C$ values in both conditions.

The HIC function is usually defined with the underlying data filtered to $1650 \mathrm{~Hz}$, so the relationship between the $1 \times 10^{4} \mathrm{~Hz}$ HIC and actual physical injury for these rapid tests can only be roughly estimated; however, the $1650 \mathrm{~Hz}$ HIC is probably inappropriate. Therefore, it is necessary to establish a physical injury model for high rate blunt trauma and correlate it to the dummy model for validation.

\subsection{Neck Injury (Nij)}

Neck injuries from blasts are possible owing to different rates of acceleration of the head and of the chest under blast loading. Physical trauma to the neck may be evaluated using the neck force transducers that may be incorporated into the Hybrid III dummy. Barring local damage to the neck itself, the dynamic impulse in the neck must be transmitted through the relative motion of the head and the chest. This transmission of force is relatively slow compared to the impact of the blast wave. Therefore, neck injuries in blast are similar in rate to impact neck injuries that have been studied in automobile safety and other contexts. There is a neck injury criterion to be used with Hybrid III dummies promulgated by the National Highway Traffic Safety Administration (NHTSA) termed the Nij criteria [14]. An injury reference value (IRV) of $N i j=1.0$ corresponds to a $30 \%$ risk of severe neck injury.

The Nij standard injury predictions were used to assess the effects of the blasts on suited and unsuited dummies. As seen in Figure 7, maximum Nij values seen in this test series were all substantially below the typical injury tolerance. This injury mode is predominantly tensionextension. Also, though all suits saw an increase in Nij with increasing charge size, suits B and D saw large increases in response from the smaller to the larger charge size while suits $\mathrm{A}$ and $\mathrm{C}$ saw smaller increases. As with the head acceleration, all suits offer protection from neck injury relative to the BLS (unprotected). The Nij criterion is the sum of the effects of neck tension/compression load, and flexion/extension moment. While the configuration of the Hybrid III neck has little axial compliance for loading in tension, in these series of tests, the maximum value of $N i j$ was,

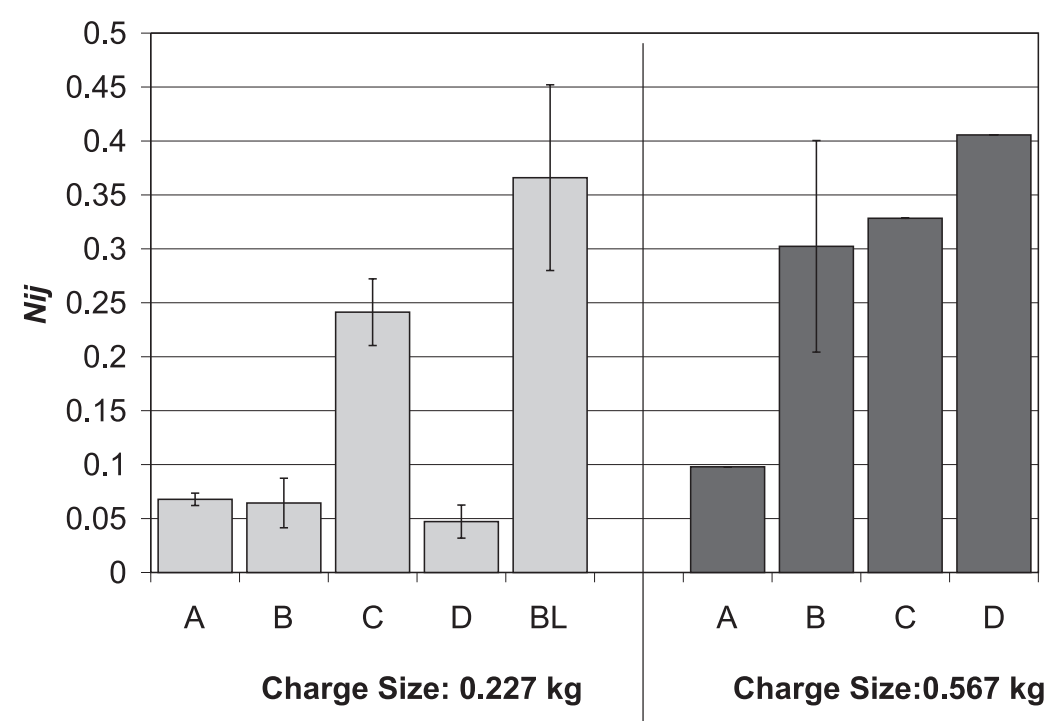

Figure 7. Maximum neck injury criterion $(\mathrm{Nij})$ values for each suit-typical injury tolerance $=1.0$ $\left(1 \times 10^{4} \mathrm{~Hz}\right.$ lowpass filter-mean value with standard deviation error bars). Notes. BL-baseline. 
on average, largely neck extension with a small amount of tension.

\subsection{Thoracic Blunt Injuries-Viscous Criterion (VC)}

Of the widely used existing thoracic blunt injury criteria, the viscous criterion developed by Viano and Lau [15] is an injury measure that seems promising for blast testing. This criterion is the product of the velocity of chest wall displacement $(V)$ and the deformation of the chest relative to the initial thickness of the thorax $(C)$. This quantity has been linked with the rate of energy storage in the thorax. A value greater than $1.0 \mathrm{~m} / \mathrm{s}$ is considered injurious.

However, there is no direct velocity measurement technique for the thorax. So, the velocity of the sternum must be inferred from displacement or acceleration measurements. Further, the original $V C$ was developed from data filtered with a low rate $(100 \mathrm{~Hz})$ filter, which is clearly inappropriate for most blast events. Therefore, the injury threshold for blast events may be different from the original standard of 1.0. In this test series, the sternal accelerometer was integrated to obtain both the velocity and the displacement. Though the displacement is small ( $\sim .001$ to $0.002 \mathrm{~m}$ ), the velocity is relatively high for this test series.

The average $V C$ values for each suit and for the unprotected dummy are shown in Figure 8.
All conditions tested show peak $V C$ values substantially lower than the usual reference injury tolerance of 1.0. However, as stated, there are significant questions as to the suitability of the usual injury tolerance for blast testing, and there is substantial spread in the $V C$ values for all suits. Similar ordering of suit performance is seen in the 0.227 and the $0.567 \mathrm{~kg}$ tests. Interestingly, the $V C$ for suit $\mathrm{C}$ is lower than for suits $\mathrm{B}$ and $\mathrm{D}$. This injury measure is one of the few for which suit $C$ performs better than suit $\mathrm{B}$ or suit $\mathrm{D}$.

\subsection{Thorax Blast Overpressure Injuries- Bowen Curves}

The evaluation of blast wave injuries is important since addition of protective equipment for the thorax may exacerbate blast overpressure injuries. Experience using body armor in Northern Ireland has shown an increased incidence of blast lung injuries, either from enhancement of the blast wave behind the body armor or from protection from usually fatal damage [18].

The three surface mounted thoracic pressure gauges generally performed well during the testing, though the right gauge failed during the test series. The peak external pressures for the protected and unprotected dummies at the 0.227 and $0.557 \mathrm{~kg}$ charge level from the upper left thorax gauges are shown in Figure 9. Owing to the presence of impulsive spikes in the data in all

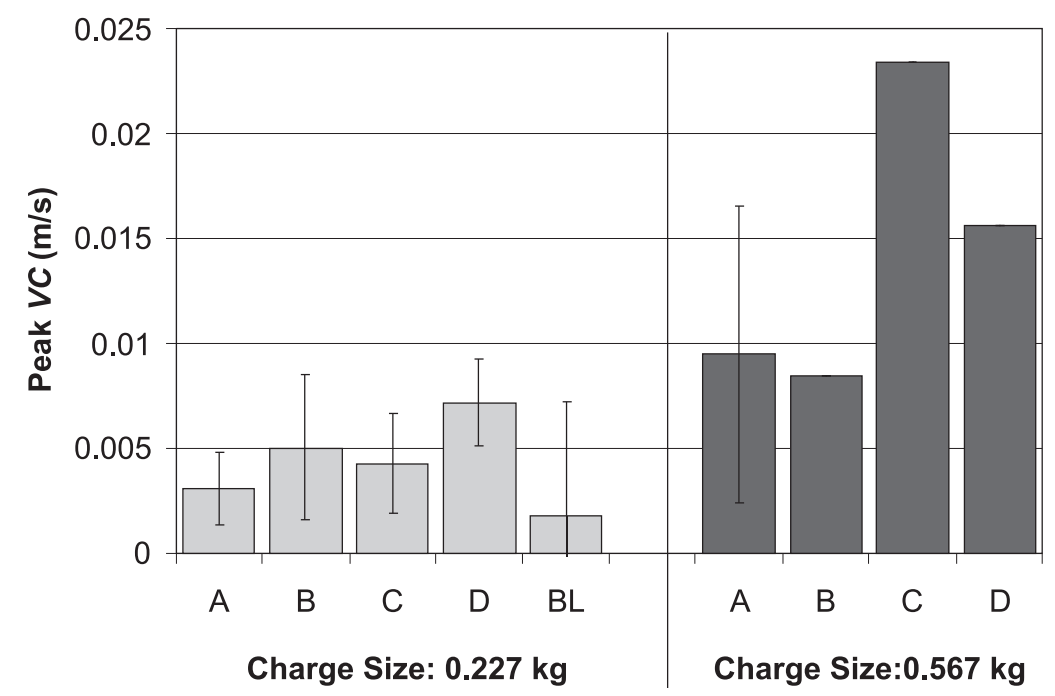

Figure 8. Variation of viscous criterion with suit type for the Hybrid III 50th percentile male dummies in the kneeling position-typical injury tolerance $=1.0 \mathrm{~m} / \mathrm{s}$ (unfiltered-mean value with standard deviation error bars). Notes. VC-viscous criterion, BL-baseline. 


\begin{tabular}{|c|c|c|c|}
\hline & Threshold lung injury & $--50 \%$ lethality & - - $1 \%$ lethality \\
\hline$\Delta$ & Suit A (0.557 kg) & Suit $\mathrm{A}(0.227 \mathrm{~kg})$ & Suit B $(0.227 \mathrm{~kg})$ \\
\hline $\boldsymbol{\Delta}$ & Suit B $(0.557 \mathrm{~kg})$ & Suit $C(0.227 \mathrm{~kg})$ & Suit C $(0.557 \mathrm{~kg})$ \\
\hline & Suit $\mathrm{D}(0.227 \mathrm{~kg})$ & Suit D $(0.557 \mathrm{~kg})$ & Unprotected $(0.227 \mathrm{~kg})$ \\
\hline
\end{tabular}

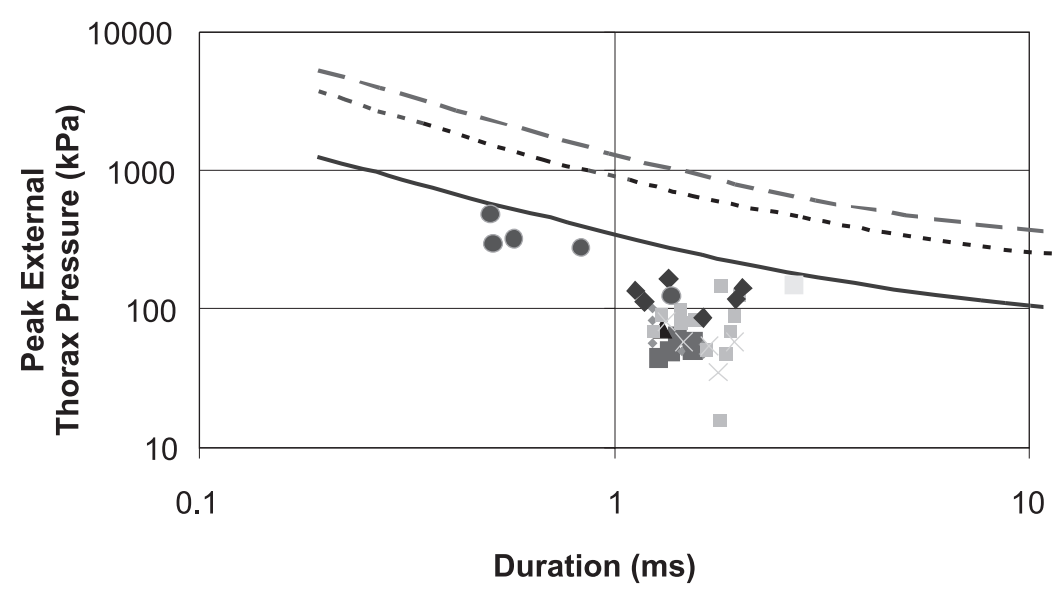

Figure 9. Peak thoracic pressure vs. duration for kneeling Hybrid III 50th percentile male dummies (suited and unsuited-2 $2 \times 10^{4} \mathrm{~Hz}$ lowpass filter).

channels, the pressure data was processed using a 15-point median filter. These are compared with the threshold lung damage free field values taken from classic work by Bowen, Fletcher, and Richmond [13]. None of the pressure time histories reaches the level of threshold blast lung injury. The pressure sensors in the unprotected dummy generally have shorter overpressure duration and greater peak pressures than those in the protected dummy. In addition, the larger charge size $(0.567 \mathrm{~kg})$ has generally larger peak pressures than the smaller charge size $(0.227 \mathrm{~kg})$. There is a significant spread in durations for a given suit and charge size though the peak pressures are relatively consistent. As pressure waves behind suits are generally complex, identification of the duration of the pressure wave is not as straightforward as with an ideal blast wave.

Average peak pressures and standard deviations for each test case are shown in Figure 10. For the $0.227-\mathrm{kg}$ charge size, mean peak pressures for suits $\mathrm{A}, \mathrm{C}$, and D are generally very consistent, though the standard deviations are relatively large for suits $\mathrm{C}$ and $\mathrm{D}$. In contrast, the center pressure

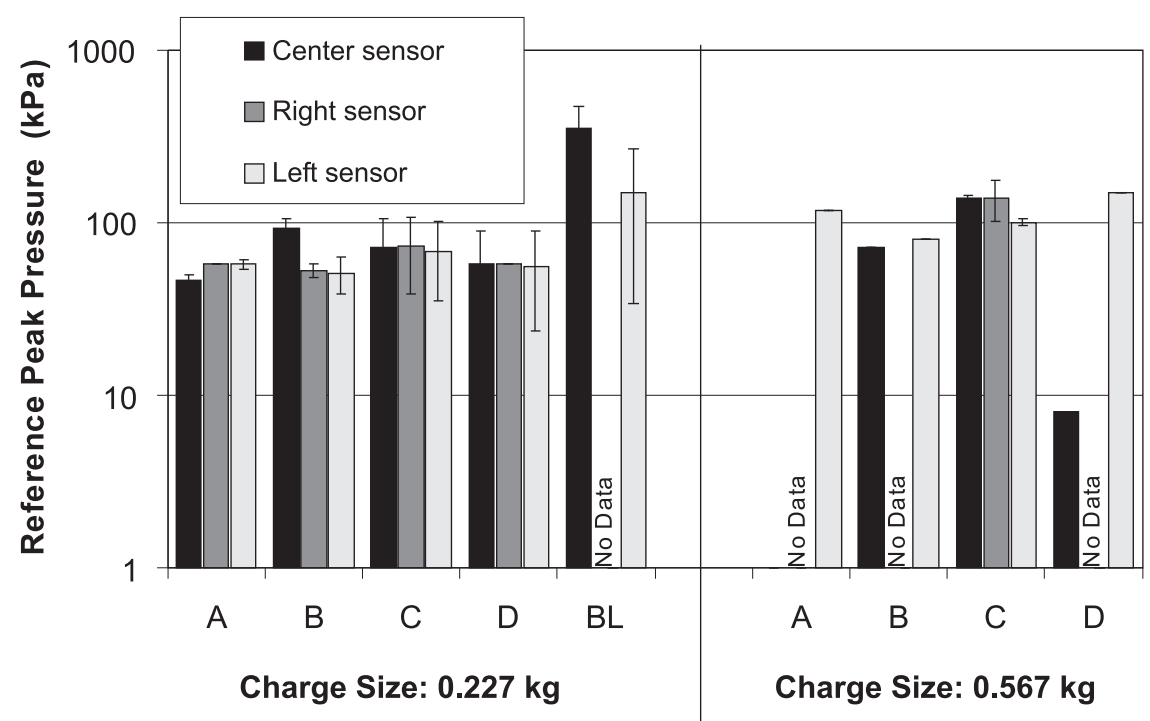

Figure 10. Peak thoracic pressure for each suit type for kneeling Hybrid III 50th percentile male dummies (suited and unsuited-2 $2 \times 10^{4} \mathrm{~Hz}$ lowpass filter). Notes. BL-baseline. 
sensor for the tests with suit B shows a substantially larger peak pressure than for the other two gauges. One explanation may be a local variation in suit geometry that exposed the center sensor relative to the left or right sensor. This phenomenon emphasizes the importance of including multiple pressure sensors in a robust test methodology. For the larger charge size $(0.567 \mathrm{~kg})$, several sensors failed during the tests making conclusions on the repeatability of response difficult. However, the peak pressures for the $0.567-\mathrm{kg}$ charge size are generally larger than those for the smaller charge size.

\section{DISCUSSION}

\subsection{Head Injury (HIC)}

To examine the effect of suit mass and area parameters on head injury, mean HIC values from the suits tested were plotted against a nondimensional area/mass $\left(\mathrm{m}^{2} \cdot \mathrm{kg} / \mathrm{m}^{2} \cdot \mathrm{kg}\right)$ ratio and the linear curve fits were determined for the four data sets as shown in Figure 11. The helmet area is nondimensionalized by the frontal area of the Hybrid III head/neck complex, and the head plus helmet mass is nondimensionalized by the mass of the Hybrid III dummy head/neck complex. This ratio of frontal area to mass was chosen because the acceleration of a head under blast pressure loading is directly related to the frontal projected area of the head or helmet, and acceleration under an applied external force is inversely related to the mass of the head/helmet. The average $R^{2}$ for this data indicated a good linear fit. The $R^{2}$ value was .81 for the $0.227-\mathrm{kg}$ charge weight and was .83 for the $0.567-\mathrm{kg}$ charge mass. It is easy to distinguish between the $0.227-\mathrm{kg}$ and $0.567-\mathrm{kg}$ charges on this plot, as the $0.567-\mathrm{kg}$ charge data has a much larger slope than the $0.227-\mathrm{kg}$ charge data.

It is clear that the nondimensional area/mass ratio is strongly related to the resulting HIC value. This correlation increases substantially with increasing charge size. Larger helmet/visor frontal areas tend to increase the risk of head injury from IED blasts from increased accelerations from increased exposure to the blast flow. Also, greater helmet mass tends to decrease the risk of head injury by decreasing the acceleration of the head/helmet/visor system. This implies that either decreasing the visor area or increasing the mass of the helmet visor system or some combination of both increases protection from blunt trauma to the head. There is, however, an obvious tradeoff for the protective value of added helmet mass. Increasing the helmet mass without regard for ergonomic factors of wearability and comfort may result in limited usage of the head protection. In addition, there is a tradeoff for the protective

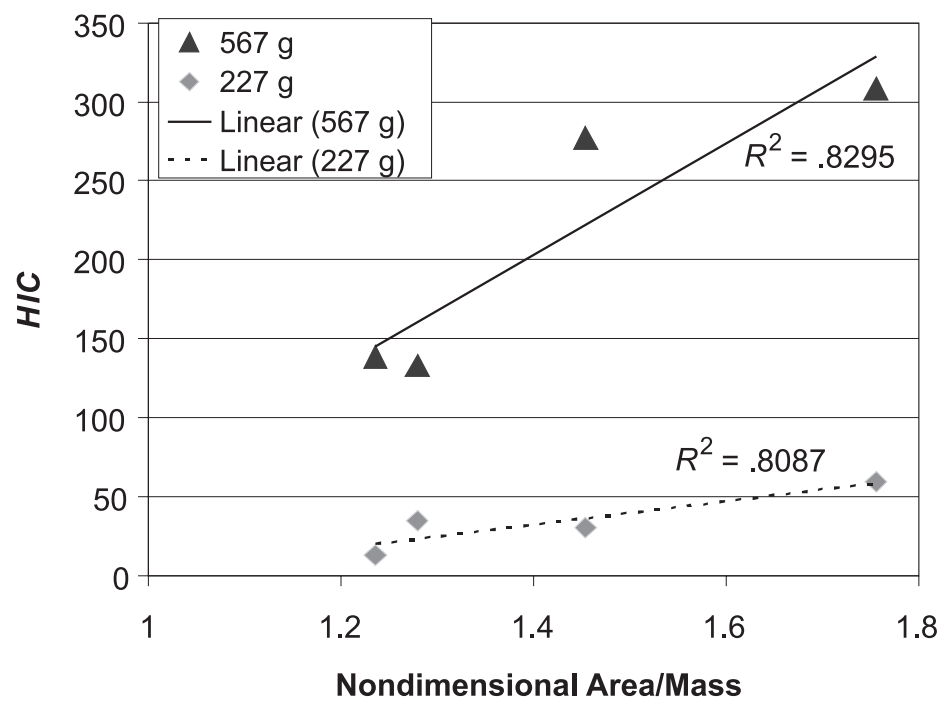

Figure 11. Variation of head impact criterion (HIC) with helmet frontal area/helmet mass for improvised explosive devices (IEDs) of 0.227 and $0.567 \mathrm{~kg}$. 
value of smaller visors/helmets. Decreasing visor/ helmet size may make the wearer more vulnerable to penetrating fragments, and may adversely affect helmet fit and impact protection.

\subsection{Neck Injury (Nij)}

One primary focus of this study was the development of a procedure to evaluate EOD suits under blast loading. Many parameters can influence the effectiveness of bomb suits, including suit/helmet mass, projected area, coverage area, and the position in which they are evaluated. For a larger projected area, more momentum from the blast is transmitted to the head. However, the additional mass of the helmet increases the inertial resistance of the head/helmet system, reducing the acceleration, delaying and reducing the peak force applied to the neck. Other variations may result from the distribution of the projected area of the helmet and face shield. The higher the projected area is on the head, the farther the resultant force of the blast is from the neck, thus creating a longer moment arm for the loading to act. However, as the force on the neck is the time-delayed result of force transmitted from the thorax and the head, it seems unlikely that neck injuries will be the dominant injury in protected EOD suit users.

\subsection{Thoracic Blunt Injury ( $V C$ )}

Though sternal displacement is often used as a thoracic blunt force injury criterion [16], thoracic wall displacements in this testing were very small $(\sim 0.002 \mathrm{~m})$. Indeed, the compression values are so small that the inherent error of the Hybrid III displacement instrumentation becomes substantial, thus limiting the statistical trends that may be inferred from the data. Further, the low displacement values suggest that sternal displacements alone have limited use as an injury criterion for blast testing.

The $V C$ is a promising injury measure for blunt traumain blast testing. It appears to discern between suits and between protected and unprotected in a robust manner. However, the injury reference value under high rate conditions remains uncertain. This could limit the usefulness for evaluating injury, unless adequate validation testing at these loading rates can be conducted. It is recommended that if $V C$ is used in injury evaluations of thoracic injury, it be used as a relative value only, pending validation with an injury model.

\subsection{Overpressure Injury}

Usual injury measures for thoracic blast overpressure injuries use side-on pressure sensors in free field blasts [13]. Such a measurement, however, is difficult to perform under body armor with a human surrogate. Therefore, a procedure must be developed to translate pressure measurements taken under the suit to the sideon pressure measurements. One straightforward approach is to use the Rankine-Hugoniot relations for ideal shock waves [19]. Assuming the ratio of specific heats for air is 1.4 , the relationship between a reflected pressure (face-on) and a sideon pressure is

$$
P_{\mathrm{R}}=P_{\mathrm{S}} \bullet\left(7 \mathrm{P}_{0}+4 P_{\mathrm{S}}\right) /\left(7{ }_{0}+P_{\mathrm{S}}\right),
$$

where $P_{\mathrm{S}}$ is the side-on pressure, $P_{\mathrm{R}}$ is the faceon pressure, and $P_{0}$ is the ambient pressure. Use of this formulation raises two significant issues in near field shock studies. First, this formulation assumes that air behaves as an ideal gas, which is not satisfied within a blast shock. In current testing, ideal gas behavior is assumed. Second, in complex flow fields no sensor may have a purely reflective or a purely side-on profile. It is likely that the thoracic sensors are nearly face-on to the blast in the current experimental setup. The errors incurred in making these two assumptions are unknown. In addition, the biological effects of complex blast waves under body armor are uncertain. Further work should be performed to characterize these effects and to obtain the appropriate injury model to dummy transfer function for use with the dummy surrogate.

\section{CONCLUSIONS}

Most of the essential elements of a test methodology for assessing protection from IED blasts were suitably defined in this proposed test methodology. The IED surrogates show repeatable pressure time histories, and the use of spherical C-4 charges provides greater repeatability from 
test to test. However, the largest simulated IED may have been too small to explore the upper limit of potentially survivable IEDs. In addition, the injury criteria used in this study were not validated against an injury model. This is necessary for full confidence in the predictions from the dummy surrogate. Further, the current test methodology addresses only blast protection. The important area of fragmentation protection may be addressed using existing standards for fragmentation resistance of armor materials.

The Hybrid III dummy has been found to be a robust and repeatable surrogate. None of the dummies used suffered a significant mechanical failure during the testing. The dummies are available in sizes that are anthropometrically similar to a human mid-sized male and similar to a small female. Positioning was accomplished to within $\pm 0.003 \mathrm{~m}$ relative to the center of the IED surrogate with an inexpensive measurement device. The kneeling position was specified to produce a significant risk of blunt head trauma to an unprotected dummy, while representing a common EOD work position.

Numerous tradeoffs are required in the design of an EOD bomb suit that protects against fragment, blast, heat, and impact, while allowing the user to accomplish the mission safely and efficiently. A comprehensive bomb suit assessment will include the evaluation of ergonomics, fragmentation protection, heat protection, and all aspects of blast induced trauma protection. These tradeoffs and assessments underscore the value of bomb suit assessment as a system, including the human as an integral system component.

\section{REFERENCES}

1. Bass CR, Boggess B, Davis M, Sanderson E, Di Marco G, Chichester C. A methodology for evaluating demining personal protective ensembles for AP landmines [abstract]. In: UXO/Countermine Conference [proceedings]. New Orleans, LA, USA: UXO/ Countermine Conference; 2001.

2. Department of Defense. V50 ballistic test for armor (Standard No. MIL-STD-662F). Washington, DC, USA: Department of Defense; 1997.
3. North Atlantic Treaty Organization (NATO) Military Agency for Standardization Agreement. Design criteria for fragmentation protective body armour (Standard No. STANAG-2920). 2nd ed. Brussels, Belgium: NATO, 1989.

4. Cooper GJ, Jonsson A. Blast overpressure injury. In: Cooper GJ, Dudley HAF, Gann DS, Little RA, Maynard RL, editors. Scientific foundations of trauma. New York, NY, USA: Butterworth Heinemann; 1997. p. $258-83$.

5. Clemedson CJ, Jonsson A. Effects of the frequency content in complex air shock waves on lung injuries in rabbits. Aviat Space Environ Med 1976;47:1143.

6. Richmond DR, White CS. Biological effects of blast and shock (Report DASA 1777). Washington, DC, USA: Defense Nuclear Agency; 1966.

7. Axelsson H, Yelverton JT. Chest wall velocity as a predictor of nonauditory blast injury in a complex wave environment. $\mathrm{J}$ Trauma 1996;40(3):S31-7.

8. Gibson PW. Amplification of air shock waves by textile materials. Journal of the Textile Institute 1995;86:119-28.

9. Young AJ, Jaeger JJ, Phillips YY, Yelverton JT, Richmond DR. The influence of clothing on human interthoracic pressure during airblast. Aviat Space Environ Med 1985;56: 49-53.

10. Phillips YY, Mundie TG, Yelverton JT, Richmond DR. Cloth ballistic vest alters response to blast. J Trauma 1988;28(Suppl.): S149-52.

11. Hayda R, Harris RM, Bass CD. Blast injury research: modeling injury effects of landmines, bullets, and bombs. Clinical Orthopaedics and Related Research 2004; (422):97-108.

12. Wolff KS, Prusa AM, Wibmer A, Rankl P, Firbas W, Teufelsbauer H. Effect of body armor on simulated landmine blasts to cadaveric legs. J Trauma 2005;59(1):202-8.

13. Bowen IG, Fletcher ER, Richmond DR. Estimate of man's tolerance to the direct effects of air blast (Report DASA 2113). Washington, DC, USA: Defense Nuclear Agency; 1968. 
14. Versace J. A review of the severity index. In: Proceedings of the Fifteenth Stapp Car Crash Conference. Warrendale PA, USA: Society of Automotive Engineers; 1971. p. 771-96.

15. Patrick LM, Lissner HR, Gurdjian ES. Survival by design - head protection. In: Proceedings of the Seventh Stapp Car Crash Conference. Warrendale PA, USA: Society of Automotive Engineers; 1963. p. 482-99.

16. Eppinger R, Sun E, Kuppa S, Saul R. Supplement: development of improved injury criteria for the assessment of advanced automotive restraint systems-II. Washington, DC, USA: U.S. Department of Transportation; 2000.
17. Viano DC, Lau IV. A viscous tolerance criterion for soft tissue injury assessment. J Biomech 1988;21:387-99.

18. Mellor SG, Cooper GJ. Analysis of 828 servicemen killed or injured by explosion in Northern Ireland 1970-1984: the hostile action casualty system. Br J Surg 1989;76:1006-10.

19. Iremonger M. Physics of detonations and blast waves. In: Cooper GJ, Dudley HAF, Gann DS, Little RA, Maynard RL, editors. Scientific foundations of trauma. New York, NY, USA: Butterworth Heinemann; 1997. p. 189-99. 